\title{
Economic motives to attend university: a cross-country study
}

(accepted for publication in Research in Post-Compulsory Education)

Brendan Bartram, Institute of Education, University of Wolverhampton, Walsall, UK

Dr Brendan Bartram,

Institute of Education,

University of Wolverhampton,

Gorway Road,

Walsall,

WS1 3BD

UK

Email: b.bartram@wlv.ac.uk

\begin{abstract}
:
This paper considers students' economic motives to attend university. Drawing on selected results from a tri-national survey involving online questionnaires and interviews with students at English, German and Portuguese universities, it examines and compares this particular extrinsic motivational dimension, alongside the influence of the national economic contexts within which the students are located. The findings suggest a strong consensus across all three settings in relation to high levels of motivation driven by the students' economic goals - careers, qualifications and future income - irrespective of background variables and fee structures. An exploration of the impact of the broader economic climate, however, reveals a more fragmented picture. The differences revealed between national settings offer tentative evidence that the students' perceptions of their country's economic situation does have a differential impact on their decision to take up university studies.
\end{abstract}

Key words: student motivation; economic impact; higher education; Germany; Portugal; England 


\section{Economic motives to attend university: a cross-country study}

\section{Introduction}

Current discourses of economic austerity, competition and employability pervade political thought, media attention and indeed everyday life in different ways. Higher Education (HE) is no exception to these discursive influences. Against this backdrop, as Zusman (2004) points out, most attention has been directed at national and institutional responses to these economic conditions. This paper, however, aims to scrutinise the perspectives of those who are arguably HE's most important 'users' - its students. A specific focus on students' economic entry motives at universities in England, Germany and Portugal aims to offer an indicative examination of how these discourses penetrate student aspirations in 3 different socio-economic settings. This innovative transnational focus hopes to provide a lens on how these influences and discourses might be culturally mediated and inflected.

Though the student experience is a common focus of study, research exploring how the current economic climate is impacting student thinking in different contexts is relatively under-explored, despite several authors (e.g. Winn, 2002, 445) identifying this as a worthwhile area of enquiry some years ago. As such, the paper aims to develop our understanding of and provide some insights into the relationship between student enrolment motives and the economic climate in Europe. The following questions are the paper's central concerns:

1. Are students' entry motivations driven by career and qualification concerns?

2. Are students' entry motives influenced by broader economic considerations?

\section{Literature Review: Students' Motivation in HE}


A reading of the literature reveals a number of common constructions of 'the student,' each associated with a distinctive motivational orientation. One construction sees students today as highly motivated 'consumer-investors' (Shahjahan et al, 2014). Leathwood and O'Connell (2003, 599), among others, have also identified the same "active consumers of educational services, taking responsibility for their own learning as independent, autonomous and selfdirected individuals," though they take exception to what they see as a masculinist, Western dimension to this framing. Askelund and Payne (2006) suggest that post-modern society pushes students towards adopting this consumerist identity in order to navigate and negotiate modern challenges and uncertainties. Elsewhere in the literature, however, (see Kneale and others below) the consumerist construction is at times associated with lower levels of subject interest and motivation. This first consumer-investor construction is also somewhat at odds with a view of a rather less motivated 'new' student, reflected in the remarks below expressed by Baroness Warnock (House of Lords Hansard, 2002):

I believe that one way or another, we should stop filling our universities with students who displayed no interest in academic matters at school, whose talents are more practical than theoretical, and who will not change. They may proceed to university for a variety of motives: because they are very bright; because they like the idea of student life; or because they have been led to believe in what has been referred to as the 'myth' that obtaining a degree will make them necessarily individually more employable and lead to a better salary. But too few of them have any interest in continuing to learn.

Leathwood and O'Connell (2003, 611) and others (e.g. Bowl, Cooke \&Hockings, 2008) question the extent to which such descriptions emerge from individual deficits or are 
constructed through social inequalities and discrimination. In their study examining students' motives for entry to HE, $50 \%$ agreed that earning money was indeed a major motivation for them, though a higher $67 \%$ suggested that their choice was in fact based on subject interest. In a similar study carried out by Winn in 2002, however, only $15 \%$ of participants indicated that subject interest was the main reason for their studies. Leathwood and O'Connell did note a widespread student preference for work-related learning but argue that such instrumental motivation did not simply "stem from a desire to earn a lot of money or get a good job, but rather (or also) a defence against getting nowhere and having nothing." In terms of class influence, Loeber and Higson's (2009) study of UK and German students identified social class as less influential in moulding UK students' study aspirations than in Germany. The authors also note, however, that intrinsic factors were the main entry motives for students in both national settings, though Kennett, Reed \& Lam's (2011) study suggested intrinsic motives were more pronounced among higher year undergraduates, first year students endorsing more extrinsic motives for entry. The authors discuss how a greater enjoyment of learning that accompanies developing maturity may eventually begin to eclipse initially more dominant instrumental concerns. Phinney, Dennis \& Osorio $(2006,347)$ suggested that ethnicity may also be important, based on findings from their US-based study, which revealed that "ethnic minority students gave greater importance to family oriented motives than did European Americans."

In the study mentioned above by Winn (2002), student participants were categorised into three groups based on motivation: an intrinsically motivated group of (generally more mature) students with demanding family and professional responsibilities but committed to their studies; a second group of less motivated students with similarly demanding responsibilities who focussed their efforts on assignment completion and opted out of activities and exercises unless directly assessed; and a third group of (generally younger) 
students with few outside responsibilities and little inclination towards their studies, despite an interest in achieving positive outcomes. Winn expresses some concern about this group in particular:

These interviewees had an instrumental approach to their studies, aiming to do the minimum of academic work required. The experiences of these students raise issues about the nature of student motivation. These students are motivated to pass their assessments and attain a degree; indeed, one student says she is motivated to achieve a first. If, as is the case in much recent higher education policy, economic outcomes in terms of a degree which will lead to employment are prioritised over the process of learning and intellectual development, then these students may be considered to be motivated. (Winn 2002, 453)

Again, such concerns are echoed internationally across the literature. Taylor's (2004) study of US undergraduates describes the current generation of students as "the most academically disengaged [...] students with all-time low measures for time spent studying and all-time high measures for boredom and tardiness, grade inflation notwithstanding." Kneale (1997) also expresses concern about a group of students perceived to be at odds with a university culture that assumes students wish to be there and are interested in their degrees, while Higgins et al $(2002,59)$ express the same concerns about strategic students who "conceive assessment tasks as obstacles to overcome in the pursuit of grades." No doubt some students have always adopted such an orientation, but Round suggests that a modern shift in expectations may be involved:

'Students now tend to see university as a means to an end rather than an experience.' $(2005,153)$ 
In the USA again, Berrett (2015) offers recent survey evidence for what is described as a marked shift from predominantly intrinsic motivations for university entry in the latter part of the 20th Century, towards more instrumentally inflected orientations today.

Returning to Winn's study, she goes on to highlight the conspicuous absence of a fourth group in her research - students with few outside responsibilities but highly motivated towards their studies. She acknowledges that such students must of course exist, but methodological limitations may be responsible for their exclusion from her investigation. Whatever the case may be, Round $(2005,9)$ argues that many university staff in the UK and internationally "are dismayed at levels of student preparation and motivation," though there is of course a wealth of studies which examine the many and various ways in which teaching staff can actively attempt to facilitate student motivation and engagement (Entwistle and Ramsden, 1983; Laurillard, 2002; Brophy, 2010; McCabe and O’Connor, 2014). In her study of over 300 undergraduates at a modern English university, Round acknowledges the complexities of attempting to capture an overall picture of student motivation:

It is almost completely meaningless to talk about students as a uniform group. The student body is now so large and diverse $[\ldots]$ that there is an enormous variety of aspirations, interest and attitudes to almost every aspect of student life. (p.3)

Nonetheless, key figures from her study are of interest here. As many as $85.9 \%$ of respondents expressed improved job prospects as their main reason for entering HE (cf. 92\% in a study carried out by Higgins et al, 2002, 53); only 53.8\% suggested it was down to subject interest (cf.71\% in Higgins et al, 2002), and even fewer (37.5\%) because of a general enjoyment of study. As many as $45 \%$ revealed a strategic attitude in admitting that they did the minimum amount of work required (p.13). Round states that the majority of students in the study agreed with the statement "I find the course boring but will stick with it because of 
getting a job". The following quotation encapsulates some of the key concerns reflected in much of the above work:

...there is considerable evidence that a particular problem for student retention and satisfaction is the existence of a group of students who are distinctly unmotivated, and whose primary consideration is to do as little academic work as possible at university while still gaining some sort of paper qualification. They are sometimes termed as 'strategic' students because their primary characteristic is the adoption of a 'strategy' which will allow them to 'get by.' Interest in their subject is sparse among this group; attendance is poor, and they will do little or no work which does not achieve a mark which contributes to their final degree qualification. This is the group who, if they are only required to pass a certain number of module in order to progress, will ignore one unit altogether and accept that they are going to miss out on the skills and content of that part of the course. (Round, 2005, 43)

\section{Economic Influences on Student Motivation}

So far, then, the literature suggests a fragmented view of student motivation in HE, an unsurprising picture, given the sheer diversity of university student constituencies, and the various factors which can influence motivation. Round (2005) offers a concise summary of such influences, ranging from levels of course satisfaction, to inherent subject interest, relationships with students and staff, teaching methods and facilities, assessment, confidence, and family, among many others. Though the picture is diverse, there do appear to be some common concerns about motivational problems. This section aims to explore what the literature tells us about the ways in which the specific contextual factor at the heart of this paper - current economic conditions - articulate with aspects of student motivation. 
To date, it would appear that few studies have directly addressed the impact of the recent economic recession on student motivation. From a more general perspective, Field $(2010,2)$ comments on research carried out in Scotland looking at the most visible impacts on HE these include an increase in demand for university places, "as young people delay entry to a hostile market," a growth of part-time students, and of students opting to study at commutable locations. He also notes an increase in students choosing degree courses linked more obviously to career specialisms, hinting thus at the possibility of degree choices based more on instrumental motives. Leathwood \& O'Connell $(2003,603)$ echo this trend in relation to 'new students' in the UK, i.e. those attending university since the birth of HE expansion initiatives, though they remain sceptical about whether such students genuinely "are most interested in vocational programmes, with the benefits framed in terms of economic benefits."

There can be little doubt that understandings of what a university is are created and sustained by "socially prevalent and culturally distinct discourses" (Read, Archer \& Leathwood, 2003, 262), and Kok and Ang $(2013,1)$ are far from alone in suggesting that education in the global north "has become increasingly driven by economic forces and it is now seen as a way to advance economic growth and prosperity," with universities in particular coming to be seen as economically rationalised institutions aimed at improving competitiveness. Cowen (1996, 447) comments on the way in which this economic framing has potentially re-configured expectations:

The drive to make higher education relevant to national economic needs placed the emphasis on vocationalism and the extrinsic value of education in terms of its employment outcomes; the liberal idea of the pursuit of education for its own sake has been increasingly undermined. 
Round $(2005,49)$ similarly refers to a changing cultural climate that has instrumentalised the idea of a university and results in societies where "students are likely to encounter attitudes which present the university as offering financial rather than intellectual opportunities." Supporting such ideas, Kok and Ang's research identified "the primacy of economic considerations when students make a choice about their education," $(2013,1)$ and provides some evidence for ideas previously discussed about the ways in which post-modern society has arguably prioritised values that emphasise competitiveness, short-term gains and economic self-interest. The Malaysian students in their study were motivated overwhelmingly by economic aspirations, and favoured courses with strong vocational elements offering labour market value over those focussing on personal development and the pursuit of knowledge. This is once again reminiscent of the student as consumer ideology, driven, as Johnstone and Usher $(1997,144)$ see it, by the post-modern tendency for social identities to index consumer orientations. Read, Archer \& Leathwood (2003, 273) suggest that this economically-inflected identity is potentially attractive to both new and traditional students:

By repositioning themselves as 'empowered' consumers, both 'traditional' and 'nontraditional' students are able to place themselves in a more central position in the world of the academy.

Johnstone and Marcucci (2007) explore world-wide trends in funding arrangements for HE, which include much-publicised reductions in government funding and increases in student costs. Their analysis highlights that economic and financial pressures are part of the dramatic intellectual, ideological and political changes referred to above. In her account of the Australian situation, Thornton $(2014,4)$ echoes these ideas and links the introduction of neoliberal funding reforms to both the student-consumer construction and associated instrumentalising effects on student motivation, and indeed institutional responses: 
"A user-pays system inevitably encourages the teaching of applied knowledge and more vocationally oriented courses as student-consumers are necessarily concerned about the return on their investment."

In his comparative case study of English and German students, Budd (2014) acknowledges these widespread concerns, discussing how such neo-liberal reforms based on knowledge economy ideals and market pre-occupations with positioning, rankings, fees, satisfaction surveys and complaints mechanisms, etc., may be implicated in promoting customer orientations, and how such orientations may then create passive pedagogical expectations. In his analysis, he highlights a potential neo-liberal paradox - on the one hand, the market reframing of the university positions students as responsible, self-determining actors with responsibility for their own success (perhaps the first active consumer construction discussed above); but on the other, market mechanisms such as fees in particular encourage a sense of entitlement to customer service and satisfaction that ultimately undermines this responsibility by deflecting it from student to institution, leading perhaps to the second, more passive consumer construction identified in the literature.

Nonetheless, Budd is keen to problematize the notion of the student as consumer (forthcoming) and suggests that this framing is possibly more a question of nervous scholarly anticipation than a widespread actuality supported by extensive empirical evidence. In his own research, economic rationales for study were rarely expressed as underpinning narratives for students' reasons for study, though admittedly, as the author himself acknowledges, his research was based on a small number of participants (14) at 2 universities. For all this, Budd discovered a greater instrumental orientation among the English participants, which he ascribes to greater HE marketization in the UK. He also acknowledges that "instrumentalism in itself is not entirely inappropriate, though, in that degrees have always been connected to the labour market" (Budd, forthcoming). 
Extending the lens more widely, Douglass (2010) similarly examines the HE financial landscape post-2008 recession, looking at different budgetary responses across the globe. He notes that Portugal was one of the EU countries hit hardest by the economic decline, which saw the introduction of tuition fees as part of its policy response, as was the case in England. Conversely, he notes a more supportive response on the part of the German ministry of education, where a more robust economy was arguably better placed to shield HE from harsher measures introduced elsewhere in the EU. It will be interesting to see whether these contrasting economic conditions are associated at all with different motivational priorities in the 3 national contexts.

\section{Methodology}

The research questions underpinning the enquiry are re-stated as follows:

1. Are students' entry motivations driven by career and qualification concerns?

2. Are students' entry motives influenced by broader economic considerations?

When comparing educational phenomena in different countries, a number of issues clearly need to be borne in mind and addressed. Firstly, there is a need to avoid essentialising assumptions that individual nation states operate as impermeable, self-contained entities and/or units of analysis. Dale (2005) views such approaches as a form of methodological nationalism, while Budd $(2012,5)$ highlights the reasons why individual states must necessarily be seen as porous:

Countries must not be considered impermeable units or sites of analysis. Global, regional, national and sub-national spheres in fact overlap and influence is multidirectional. 
European HE systems are particularly good examples of these multi-directional and multilayered influences, in that policy decision-making is still directed at national level (Portugal and England)/federal state level (Germany) in each country, but clearly subject to and influenced by broader international trends and common shifts (e.g. the neo-liberal ‘knowledge economy' narratives discussed earlier) and supra-regional policies emerging from the European Union's commitment to establishing a common European Higher Education Area (EHEA) since the Bologna Agreement in 1999. Against such macro-level influences, there is also the need to remember that nations are made up of inhabitants, whose preferences, priorities and understandings will be shaped by individual qualities, dispositions, and a whole host of broader socio-cultural variables. With this in mind, the value of crossnational educational comparison might be questioned, given such dynamic and fluid porosity at all levels. Its value, however, may be defended in terms of the light that such study is able to shed on commonalities and differences, and the potential factors that may account for them. Bartram $(2010,187)$ argues, for example, that "evidence of particular phenomena across a range of contexts arguably allows more weight to be attached to certain conclusions given the replication of findings across datasets." Where differences are found, the comparative lens invites us to examine the ways in which socio-cultural variables may articulate with circumstances, actors and phenomena in order to develop our understanding of complex educational issues (Crossley and Watson, 2003).

A number of decisions lay behind the choice of the three countries included in the study. All 3 are EU member states, subject to the same HE goals as dictated by EU agreements on the one hand, but shaped by separate national traditions and histories on the other. Given the study's interest in economic influence on student thinking, the 3 sites also offer a set of contrasting economic backdrops (Douglass, 2010) against which to explore this phenomenon. Financial analyses show a consistent hierarchy in economic performance between the 3 
countries, with Germany ahead of the UK, and then Portugal at some distance behind both. The World Bank (2015), for example, lists the global positions for the 3 countries as 4th, 6th and 48th, based on GDP, while the World Economic Forum competitiveness rankings show them at 5th, 9th and 36th respectively. The three countries also operate quite distinct policies with regard to degree funding - studying in the majority of the German states is still free; in Portugal, annual tuition fees apply of between EUR 630-1068, whereas English fees are generally set at around $£ 9,000$ per year (Eurydice, 2015).

It was decided to focus on undergraduates at one institution in each of the countries, and as such, the study does not claim to offer findings which are necessarily representative of the national picture (inasmuch as that exists). To offset this potential limitation and provide a degree of relatability (Hammerlsey, 1990), the universities included were purposively selected on the basis of their relative typicality - large, multi-faculty and state-run institutions offering a wide range of courses at BA/MA/D levels in the West Midlands, North-Rhine Westphalia and the Algarve. The students surveyed were all studying broadly similar subjects - this in an attempt to provide as valid a basis for comparison as possible, given the potential dissimilarity in motivations between students from different subject backgrounds and disciplines. My own location in Educational Studies led me thus to target students who had all decided to embark on a range of education and teaching-related degrees. A mixedmethods approach was adopted, consisting of an on-line questionnaire, followed by individual email interviews with students from each institution.

The students were contacted via each institution's virtual learning environment, and sent a link for completing the questionnaire. At this stage, they were also asked to declare their willingness to participate in follow-up email interviews. The short questionnaire (adapted from Neill, 2004) aimed to capture a range of student views but for the purposes of this paper, attention will focus only on those questions related to the questions identified in the 
introduction. A number of questions collected categorical details, while the others (shown in tables 1 and 2 below) required respondents to express levels of agreement (from 1: strongly agree, to 5: strongly disagree) with 8 statements relating to career/qualification motives and the influence of broader economic factors. The tables below show agreement percentages based on the 'top 2 boxes,' i.e. strongly agree and agree. The aim was to provide a numerical indication of key areas of agreement/disagreement, in an attempt to highlight commonalities and differences. It should be noted that the percentage figures used below are included here for the purposes of tentative indication, rather than statistical statement of fact - the limitations imposed by the self-selective nature of the samples, the variation in group sizes, and the single institutional and subject-area composition can only support fallibilistic interpretation (Schwandt, 2001, 91) rather than scientific measurement.

In total, 351 students completed the questionnaire - 150 UK students $(42.7 \%$ of the overall sample, and thus the largest grouping; 99 Germans (28\%) and 102 Portuguese (29\%). Of these, $17 \%$ were male, $83 \%$ female, representing thus a significant gender imbalance, though reflective of course recruitment patterns at all 3 institutions. In terms of age, $76 \%$ of the overall sample fell into the $18-25$ bracket, $17 \%$ were $26-40,7 \%$ were over 41 . There were more variations in age terms between the 3 settings, particularly with regard to the number of mature students included - in the UK sample, $18 \%$ of students were $26-40$ (12\% in Portugal and $21 \%$ in Germany); students over 41 represented $14 \%$ of the UK sample, $4 \%$ of the Portuguese but none in Germany. Students were additionally asked to state their ethnicity, though many chose not to, and as such a reliable breakdown of the sample's ethnic composition cannot be presented. All the participants had studied between 2 and 7 semesters at university.

The results of the questionnaire were then used as a basis for informing the second stage of the research, which intended to probe and develop the categories and ideas emerging from the 
questionnaires. A set of 7 open-ended interview questions were emailed to all the students who had expressed a willingness to participate in the second stage of the project, the intention being to generate more exploratory qualitative data to complement the numerical detail generated by the closed questions from stage 1, and also to offset the potential bias inherent in fixed items. Though email interviews have a number of advantages in terms of cost and time efficiency, access and reach (Meho, 2006), some limitations unfortunately became equally evident, most notably in terms of lower response rates. This might be attributed to the lack of rapport afforded by anonymous electronic approaches, and potentially also to perceptions of greater effort requirements, especially on the part of the German and Portuguese students, who were being asked questions in a second language. And despite assurances of confidentiality, student concerns here may have been an additional factor. As such, a set of responses was received from 26 students (13 English - 11 female, 2 male; 7 Germans -5 female, 2 male; 6 Portuguese -5 female). Their comments were analysed by a process of thematic coding aiming to capture the full range of themes and nuances expressed. Though the numbers of returns were fewer than hoped, this second stage was still successful in both corroborating key ideas on the one hand, and in complementing the questionnaire with a greater depth of qualitative colour on the other.

\section{Findings}

The online software package used for the questionnaire enabled filtering by place of study and converted responses into percentage totals (rounded up/down accordingly) per country to facilitate comparison. Quotations from the interviews have been included verbatim and uncorrected. With regard to the first research question concerning the strength of the 
students' qualification and career motives, the data reveal both strong alignment between the 3 groups of students and very high overall agreement, as table 1 shows below:

[insert table 1 here]

The responses to these items clearly showed overwhelming agreement that the participating students are strongly motivated to attend university by the extrinsic goals of achieving their degree qualifications in a bid to improve their professional prospects and futures, in line with previous studies (Berrett 2015, Kok and Ang 2013, Round 2005 and Higgins et al, 2002). Echoing Budd's (forthcoming) findings, the English students distinguished themselves by expressing strongest agreement with all the statements in this category (e.g. $77 \%$ of the English students expressed strong agreement with "enhancing my job prospects," cf. $44 \%$ of the Germans, and $45 \%$ of the Portuguese). This may in part reflect contrasting cultural understandings of university - Budd (forthcoming) compares, for example, the persistence of a Humboldtian university model in Germany with a more dominant market-oriented version in England that translates into a heightened instrumental awareness among students.

Given indications in the literature (e.g. Kennet, Read and Lam, 2011) that higher year students may be less inclined to endorse extrinsic motives, first year and higher-year (6-7 semesters completed) students' agreement ratings were examined separately. Differences here were marginal, however, and there were no indications that the motives of higher year students in any of the 3 countries were any less driven by these concerns than those of first years.

Data from the email interviews supported the above impressions, with all respondents volunteering qualification and career reasons among their top two priorities for attending university, as the following quotations reveal: 
"I decided to go to university because I thought obtaining a higher level of education was going to elevate me and probably open new professional doors for me. I mean let's face it, it is almost impossible to get a foot through the door if you do not have a degree and work experience unless you know somebody who already works there. And since I do not, the only way in would be to show them that I am trained and learned." (German male)

And echoing Leathwood and O'Connell (2003):

"I want to get out of my minimum wage job and secure a good paid job, better employment choices." (English female)

One Portuguese student makes a connection between growing labour market competition and university enrolment:

“Although Portugal's Government don't know what's doing the people in this country is highly qualified, dedicated and needs to be appreciated more often, but it means more pressure for us to have high qualifications as many people already have."

As Budd (forthcoming) argued previously, these findings serve to illustrate potentially longstanding student concerns with instrumental aims in that "degrees have always been connected to the labour market."

Whereas responses to the above items - issues arguably more prominently associated with the students' personal economic goals - showed strong alignment, differences with regard to broader economic considerations appeared more pronounced, however, as a consistent hierarchy emerged in the students' responses to these questionnaire items. Most notably, the German students' answers indicated that studying at university was for them less motivated by economic fears of recession/unemployment and a perceived need to strengthen their 
economic position than was the case for the Portuguese students (who expressed most agreement) and the English students, though this again might partly reflect underlying cultural differences in thinking discussed above. Clearly, all 3 groups attach some importance to wider economic concerns of this kind, but the differences in overall agreement (and indeed disagreement) ratings between the German and Portuguese constitute striking contrasts (e.g. $48 \%$ of the Germans agreed that studying was motivated by a desire 'to protect myself in today's economy cf. $86 \%$ of Portuguese and $68 \%$ English; $48 \%$ of Germans disagreed that economic fears lay behind their enrolment, cf. only $10 \%$ of Portuguese students and $31 \%$ English students, with similar differences noted for the other items.) Table 2 brings together an overview as follows:

[insert table 2 here]

As with the previous items, data from first and higher-year students were re-examined to explore any age/study-year-related differences. This time, however, larger contrasts emerged in that agreement scores for $1^{\text {st }}$ year students were consistently and conspicuously lower than those of the higher-years. Comparing the mean agreement scores for indicative purposes revealed that higher-year German, Portuguese and English students were around 13, 28 and $17 \%$ (respectively) more driven to attend university by the broader economic factors described above. These differences may potentially relate to the more immediate concerns of higher-year students closer to entering the labour market, but this remains a necessarily tentative interpretation. Despite the differences, the same national patterning is preserved here, and would again suggest that broader economic conditions are more influential for the Portuguese students. 
Once again, interview data served to strengthen the picture emerging from the above data. Not a single German student linked their primary motivation to broader economic factors, whereas references to these were common among the English students (cf. Budd again, forthcoming), and even more so among the Portuguese. As one female student commented:

"For me, my main motivation is staying above the surface of unemployment here in Portugal, I can honestly say my effort comes first to survive.”

In a bid to explore this aspect in more detail, the participants were additionally asked in the interviews to consider to what extent the cost of attending university had influenced their decision. The following response typified the essence of German responses:

“In Germany we don't have to pay tuition fees and that made the choice definitely much easier. My family wouldn't have been able to pay for a huge fee and I would have been constrained to take a loan."

For the German participants, then, going to university was not associated with economic concerns regarding financial outlay or debt, and as such, cost was not considered influential. For the English students, finance did appear more of an issue, and several of the respondents commented on initial anxieties about committing themselves to the high costs of studying at university. However, the English respondents' comments suggested that these concerns were allayed once they became more informed about the financial arrangements involved:

"The high costs made me not want to go to university at first but then I was ready to take the risk because I came to understand that I only had to pay the tuition fee back if my future income will be above a certain amount and if I get a professional salary I'd be able to pay it back in instalments." 
For the Portuguese students, the situation was less clear-cut. Some suggested the costs were insignificant, given that they were able to rely on family or parental support, or income from part-time employment. Several others, however, indicated that the costs involved had been influential, particularly in influencing their decisions to opt for more vocationally oriented degree courses (cf. Thornton, 2014):

“Cost of studying was definitely a big influence. I think money influence my whole path. Money influenced the choice of my course, I feel pressured to take a course where I know I will get good money in the future."

The students were also invited to comment directly on whether they perceived the wider economic context to have had any bearing on their motivations. Once again, most of the German students disagreed, with only one student conceding that economic factors had been influential - but for clearly very positive rather than negative reasons:

"In Germany, we have a great economy, with a lot of great job opportunities, which you only get if you hold a degree." (German female)

The English responses were more divided, some suggesting that economic concerns were peripheral, while others again expressed their awareness of labour market competition, the need to secure well-paid employment, and the link between the economic situation and future financial security:

"I feel the economic situation did influence my decision to go to university. Although I've always wanted to go into teaching, when applying to university I felt that my course choice and aspirations were safe. I didn't want to do a degree for the sake of it. I wanted an end goal in a career that I deem to be safe - teachers are always going 
to be needed, so hopefully there will always be opportunities for employment." (English female)

For the Portuguese participants, the picture which emerged from the interviews appeared much more clear-cut, however, all of them suggesting that economic concerns had played some part in influencing their decision to study. The Portuguese students were the only ones in the sample to link degree study explicitly with overseas employment as a means of escaping domestic economic challenges:

"Graduating may give me job opportunities in other countries in the EU that I may not get in Portugal at this time.” (Portuguese male)

“The economic situation influence me a lot. In our days it's so difficult to have a stable life in Portugal that the young people don't know what to do. I am one of the young adults that felt pressured to get a degree so life won't be so difficult in the years to come or so that I could escape Portugal, into foreign soil, and have a dignifying life." (Portuguese female)

\section{Discussion and Conclusions}

At this juncture, it is worth considering what the findings reveal with regard to similarities and differences between the groups of students, and what conclusions can be drawn from this. As stated throughout, these must be considered in light of the study's limitations - the singleinstitutional focus in each country; samples drawn from one academic discipline only; the self-selective nature of the samples, and the limitations of the data collection instruments described above. Furthermore, the investigation was unable to capture the views of potential students who decided against university study. An examination of their perspectives, particularly in relation to the possible deterrent of a perceived lack of economic incentives, 
would have clearly been beneficial. Nonetheless, a number of tentative conclusions can be drawn. Firstly, in terms of similarities, the paper reveals that economic entry motives related to career and qualifications are strongly endorsed by students from all three countries. This does not of course mean that these students are exclusively motivated by extrinsic factors (for a discussion of other motives, see author, forthcoming) but it does indicate that such motives are important drivers. The strong and almost overwhelming consensus additionally suggests that a number of background variables such as nationality and year of study/age - and potentially ethnicity, gender and socio-economic status - do not appear to be important influences on this particular aspect of instrumentality, lending some weight thus to Read, Archer and Leathwood's (2003) point that the appeal of the consumerist identity cuts across social divisions. Intriguingly, with regard to certain contextual variables - the differences in fee levels and structures (as noted in the English, German and Portuguese systems) do not appear to be particularly associated with this form of entry motivation either, though it is worth noting that the strongest agreement percentages were expressed by the English students who are also subject to the highest tuition fees. The replication of this picture across the contexts here is arguably useful in strengthening these assertions (Bartram, 2010), though again, the findings may to some extent be a reflection of common orientations shared by students drawn to this area of academic study.

Secondly, given that all 3 groups of students appear so strongly motivated by extrinsic desires for the credentials of university enrolment and the career advantages these are perceived to confer, the study also offers some evidence of the actively motivated educational consumers, driven by employability concerns, referred to in the literature. There is little evidence of the second, more passive 'student as consumer construction' discussed in the literature review by Budd (2014) and others, though the methodological approach adopted here has perhaps been 
less conducive to opening up an exploration of this dimension, and the sample composition and nature must again be noted.

Clearly then, the above suggests a strong consensus in relation to high student motivation driven by economic aspirations. Universities are of course already very focussed on strategies for enhancing student employability (McCowan, 2015) and these findings indicate the ongoing relevance of such endeavours from a student focus point-of-view. This consensus would appear lost, however, when it comes to an exploration of motivation driven by perceptions of the broader economic contexts within which the students are located - in this respect, a much more differentiated picture emerges. The consistency of the differences discussed between national settings arguably offers tentative evidence that (these students' perceptions of their country's) economic situation does have a differential impact on their decision to take up university studies. As discussed, the German students (who comment frequently on the perceived buoyancy of their economy) appear to be the least driven to attend university because of wider economic concerns, whereas the situation is clearly and markedly reversed in both respects in the case of the Portuguese students. As discussed previously, however, the extent to which underlying cultural differences may make the German students less inclined to frame their thinking in economic terms must be considered.

And finally, though it seems that differences in national financing structures and tuition fees had little bearing on the strength of the students' economically inflected entry motives, there appears to be some evidence here of a relationship between the above arrangements and career/course choice - the English and Portuguese students are the only ones in the study to express connections between study costs and economic climate on the one hand, and degree selection based on concerns about employment security on the other. They are also the only ones who express an awareness of crowded labour market competition, and in the case of the Portuguese students, the need to consider employment options abroad in response to these 
perceived pressures. It would be useful to explore these aspects in more detail and depth in future studies, and also to survey students across a range of subjects (and indeed other countries) to determine to what extent the above patterns are consistent across other academic disciplines and nations.

\section{References:}

Askeland, G. and Payne, M. 2006. "The Post-Modern Student: Piloting Through Uncertainty." Journal of Teaching in Social Work 26 (3/4): 167-179.

Doi:10.1300/J067v26n01-11.

Bartram, B. 2010. Attitudes to Language Learning: Insights from Comparative Education. London: Bloomsbury.

Author (forthcoming) "Career and money aside, what's the point of university? A comparison of students' non-economic entry motives in three European countries." Higher Education Quarterly.

Berrett, D. 2015 "The day the purpose of college changed." The Chronicle of Higher Education, 26 January. Accessed 15 April 2015 http://chronicle.com/article/The-Day-the-Purpose-of-College/151359

Bowl, M., Hockings, C. and Cooke S. 2008 "Home or away? Issues of 'choice', living arrangements and what it means to be a student." Widening Participation and Lifelong Learning 10 (1): 26-35

Brophy, J. 2010. Motivating Students to Learn. Abingdon: Routledge.

Budd, R. 2012 "Why might students in different countries have contrasting views of higher education? Do they?" Paper presented at the World Universities Network (WUN) 'Ideas and Universities' Seminar, Bristol, UK, 25th of October 2012.

Budd, R. 2014. Students as Neo-Institutional Actors: A Comparative Case Study of How German and English Undergraduates Understand, Experience and Negotiate Higher Education, PhD diss., University of Bristol.

Budd, R. (forthcoming) "Undergraduate orientations towards higher education in Germany and England: problematizing the notion of 'student as customer,"' Higher Education Crossley, M. and Watson, K. 2003. Comparative and International Research in Education. London: Routledge Falmer. 
Cowen, R. 1996. "Performativity, post-modernity and the university." Comparative Education 32: 245-258.

Dale, R. 2005. "Globalisation, Knowledge Economy and Comparative Education." Comparative Education 41(2), 117-149.

Douglass, J. 2010. "Higher Education Budgets and the Global Recession: Tracking Varied National Responses and Their Consequences." Center for Studies in Higher Education Accessed 30 October 2014 http://escholarship.org/uc/item/44m4p8r4

Entwistle, N.J and Ramsden, P. 1983. Understanding Student Learning. Beckenham: Croon Helm.

Eurydice. 2015. "National Student Fee and Support Systems in European Higher Education." Accessed 9 June 2015

http://eacea.ec.europa.eu/education/eurydice/documents/facts_and_figures/fees_support.pdf

Field, J. 2010. "Higher education and the recession: the early impact in Scotland." Paper presented at Scottish Educational Research Association Annual Conference, Stirling Highland Hotel, 26 November 2010.

Hammersley, M. 1990. Reading Ethnographic Research. New York: Longman.

Higgins, R., Hartley, P. and Skelton, A. 2002. "The conscientious consumer: reconsidering the role of assessment feedback in student learning." Studies in Higher Education 27 (1): 53 64.

House of Lords Hansard. 2002. University Finance Debate: Baroness Warnock 641(9) 27 November 2002.

Johnstone, D. and Marcucci, P. 2007. "Worldwide Trends in Higher Education Finance: Cost-Sharing, Student Loans, and the Support of Academic Research."

Accessed 25 March 2015

http://unesco.amu.edu.pl/pdf/Worldwide_Trends_in_Higher_Education_Finance_CostSharing \%20Student\%20Loans.pdf

Johnston, R. and Usher, R. 1997 "Re-theorising experience: adult learning in contemporary social practices." Studies in the Education of Adults, 29, 37-153.

Kennett, D., Reid, M. and Lam, D. 2011. "The importance of directly asking students their reasons for attending higher education." Issues in Educational Research, 21(1): 65-74.

Kneale, P. 1997. "The rise of the 'strategic student': how can we adapt to cope?" in Facing up to Radical Changes in Colleges and Universities edited by S. Armstrong, G. Thompson and S. Brown. London: Kogan Page. 119 - 130. 
Kok, J. and Ang, S. 2013. "Liquid modernity and choice of university degree programmes: Malaysian university students' perception.” Journal of Sociology Published online before print July 17, 2013, doi: 10.1177/1440783313492236.

Laurillard, D. 2002. Rethinking University Teaching. Abingdon: Routledge.

Leathwood, C. and O'Connell, P. 2003. 'It's a struggle: the construction of the 'new student' in higher education." Journal of Education Policy, 18 (6): 597-615

Loeber, S. and Higson, H. 2009. "Motivation to study in Higher Education: a comparison between Germany and Great Britain.” Higher Education in Europe 34 (3-4): 511-521.

McCabe, A. and O'Connor, U. 2014.'Student-centred learning: the role and responsibility of the lecturer." Teaching in Higher Education 19 (4):350-359

McCowan, T. 2015. "Should universities promote employability?" Theory and Research in Education 13 (3): 267-285.

Meho, L. 2006. "E-Mail Interviewing in Qualitative Research: A Methodological Discussion." Journal of the American Society for Information Science and Technology 57 (10): 1284-1295.

Neill, J. 2004. "The University Student Motivation and Satisfaction Questionnaire version 2. (TUSMSQ2)" Centre for Applied Psychology: University of Canberra.

Phinney, J., Dennis, J. and Osorio, S. 2006. "Reasons to attend college among ethnically diverse college students." Cultural Diversity and Ethnic Minority Psychology 12 (2): 347-366

Read, B., Archer, L. and Leathwood, C. 2003. "Challenging Cultures? Student Conceptions of 'Belonging' and 'Isolation' at a Post-1992 University.' Studies in Higher Education 28 (3): 261-277.

Round, A. 2005. A Survey of Student Attitudes, Experiences and Expectations, Student Retention Project, University of Northumbria Research Report.

Schwandt, T.A. 2001. Dictionary of Qualitative Enquiry. London: Sage.

Shahjahana, R., Morgan C. and Nguyen, D. 2014. "Will I learn what I want to learn?' Usable representations, 'students' and OECD assessment production." Discourse: Studies in the Cultural Politics of Education, published online first at DOI:10.1080/01596306.2014.986715

Taylor, M. 2004. "Generation neXt comes to college: meeting the postmodern student." Higher Learning Commission Collection of Papers.

Accessed 12 February 2015

Http://www.taylorprograms.org 
Thornton, M. 2014. Introduction: the retreat from the critical, in Through a Glass Darklythe Social Sciences Look at the Neoliberal University, edited by M. Thornton, Canberra: ANU Press.

Winn, S. 2002. "Student Motivation: a socio-economic perspective." Studies in Higher Education 27 (4): 445-457.

World Bank. 2015. “World Bank Indicators Database."

Accessed 9 November 2015

http://databank.worldbank.org/data/download/GDP.pdf

World Economic Forum. 2015. "Global Competitiveness Forum."

Accessed 9 June 2015

http://www3.weforum.org/docs/WEF_GlobalCompetitivenessReport_2014-15.pdf

Zusman, A. 2004. "Challenges Facing Higher Education in the Twenty-First Century." Accessed 20 March 2015

http://www.educationanddemocracy.org/Resources/Zusman.pdf

Table 1: Qualification and career (personal economy) motives - agreement percentages

\begin{tabular}{|l|l|l|l|}
\hline I decided to go to university.... & Germans & Portuguese & English \\
\hline To enhance my job prospects & 97 & 100 & 98 \\
\hline To get the qualification & 96 & 93 & 94 \\
\hline Because it will help my career & 97 & 86 & 98 \\
\hline So I can get a better job & 96 & 88 & 92 \\
\hline Mean percentage agreement & 96 & 92 & 95 \\
\hline
\end{tabular}

Table 2: Broader economic climate factors - agreement percentages

\begin{tabular}{|l|l|l|l|}
\hline $\begin{array}{l}\text { Broader economic factors: I decided to } \\
\text { go to university.... }\end{array}$ & Germans & Portuguese & English \\
\hline To guard against future unemployment & 44 & 62 & 67 \\
\hline To protect myself in today's economy & 48 & 86 & 69 \\
\hline $\begin{array}{l}\text { Because of fears about economic } \\
\text { recession }\end{array}$ & 26 & 65 & 33 \\
\hline To improve my economic position & 67 & 81 & 73 \\
\hline Mean percentage agreement & 46 & 74 & 60 \\
\hline
\end{tabular}

